\title{
Occupational Hazards among Neurosurgeons: Do We Need to Change Our Habit?
}

\author{
Pankaj Raj Nepal ${ }^{1}$ \\ ${ }^{1}$ Department of Neurosurgery, B \& C Medical College and Teaching Hospital \& \\ Research Center, Birtamode, Jhapa, Nepal \\ Correspondence: \\ Dr. Pankaj Raj Nepal \\ Deputy Hospital Director, Head of Department, Department of Neurosurgery, B \& C \\ Medical College and Teaching Hospital \& Research Center, Birtamode, Jhapa, Nepal. \\ Email: pankajrajnepal@gmail.com \\ Phone: +9779801098106
}

$\mathrm{T}$ There are various types of occupation related problems. Some of them are well noticed and other might be slowly and unnoticeably harming professionals. Hazards are classified vaguely into accidental, chemical, biological, ergonomic, psychosocial and organizational hazards. The accidental hazards are usually quickly noticed by the professionals like, stab, cut, pricks, cautery burn and so on. ${ }^{1-5}$

For neurosurgeon, besides accidental, chemical, biological hazards, there might be more important issue regarding ergonomic and psychosocial hazards. As neurosurgeon are well known for their very long standing surgeries by maintaining difficult posture in a small area, they might be having special risk of having degenerative spine pathologies, especially cervical and lumbar spine. ${ }^{6}$ Along with these, long hours of wearing latex gloves they are also at increased risk of having contact dermatitis and skin scaling. ${ }^{1,2}$

The long duty hour stressful surgeries and patient care and counseling make them busy most of the time. The result of which they might have limited quality time to spend with their families and friends, the result of which, they are prone to have poorly managed family life and also at risk of divorce among married couples when compared with other non medical profession. ${ }^{7}$

Though the exact cause of Alzheimer is poorly understood, the neurosurgeons seems to have special risk of harboring this disease. $^{8}$

The special attention might be required for neurosurgeons to prevent with these occupation hazards. A regular physical therapy, especially prone extension and pectoralis stretch were advised to prevent kyphotic posturing that could develop with prolong standing surgeries. ${ }^{6}$ Mind relaxation technique and occasional outing with families might be good option to prevent from psychosocial hazards. 


\section{References:}

1. Memon AG, Maeem Z, Zaman A, Zahid F. Occupational health related concerns among surgeons. International Journal of Health Sciences, Qassim University 2016;10(2): 280-291.

2. Salahuddin O, Qadir A, Aslam MN. Occupational Hazards for Surgeons. Annals of King Edward Medical University Lahore Pakistan 2005;11(4):568.

3. Jiménez PR, Pavés CJR. Occupational hazards and diseases among workers in emergency services: a literature review with special emphasis on Chile Medwave 2015;15:e6239,1-8.

4. Taylor C1, Graham J, Potts H, Candy J, Richards M, Ramirez A. Impact of hospital consultants' poor mental health on patient care. Br J Psychiatry 2007;190:268-269.

5. Green A1, Duthie HL, Young HL, Peters TJ. Stress in surgeons. Br J Surg. 1990;77:1154-1158.

6. Neal CJ, Oelschlaeger K. Exercise for the Surgeon: Counteracting the Effect Surgery Takes on the Surgeon. AANS Neurosurgeon 2017;26 (4)

7. Zil-E-Ali A, Awana MT, Aadil M. Relationship Issues and High Divorce Rate among Surgeons. JCPSP 2017;27(11): 739.

8. Lollis SS, Valdes PA, Li Z, Ball PA, Roberts DW. Cause-specific mortality among neurosurgeons.

Neurosurg. $2010 \quad$ Sep; 113(3):474478. doi: 10.3171/2010.1.JNS0917 